http://doi.org/10.46754/gtc.2021.11.019

\title{
CUSTOMER RESTAURANT SELECTION FACTORS IN VEGAN RESTAURANTS: AN EVALUATION OF ONLINE REVIEWS IN MELBOURNE VEGAN RESTAURANTS
}

\author{
Anh Viet Le', Thu Huong Nguyen² \& Joel Francis F. Hernandez ${ }^{3}$ \\ ${ }^{1}$ Holmes Institute, Melbourne Australia \\ ${ }^{2}$ Victoria University, Melbourne, Australia \\ ${ }^{3}$ The Hotel School - Southern Cross University, Melbourne, Australia \\ (ale@holmes.edu.au, thu-huong.nguyen@vu.edu.au,j.hernandez.11@student.scu.edu.au)
}

\begin{abstract}
Restaurants are constantly adapting towards customers' wants and needs. Vegan restaurants have become increasingly popular, particularly in Melbourne, which is one of the fastest growing vegan markets in the world. While there is literature and evidence of restaurant selection factors in general restaurants, there are no specific studies in vegan restaurants. The aim of this study is to determine the customer restaurant selection factors in vegan restaurants by way of a qualitative content analysis of 5 popular Melbourne vegan restaurants with 10 reviews each. This study found that similar to general restaurants that serve meat, vegan restaurants are chosen mainly because of their food quality and service quality. Vegan restaurants must continue to build on the quality of their food and prioritize putting the same amount of focus on service quality, as poor service quality can completely tarnish the entire dining experience.
\end{abstract}

KEYWORDS: Vegan restaurant, online review, selection factors, sustainable

\section{PURPOSE AND BACKGROUND}

The restaurant industry is constantly adapting as the modern customers are seeking new dining experiences based on evolving wants and needs. Plant-based foods which include the vegetarian and vegan diets have become increasingly popular in recent years as people are looking for more sustainable options for health, ethical, and environmental reasons (Melina, Craig \& Levin, 2016).

Customers are always looking for value for their money and use the internet to find out information about an establishment when dining out. While there is enough information and literature on the restaurant selection factors for general restaurants, there is limited research on plant-based focused restaurants.

The purpose of this research is to explore the restaurant selection factors of vegan restaurants in Melbourne, where the plant-based dining scene is thriving and currently one of the fastest growing vegan markets in the world. Moreover, the scope of this research will focus mainly on Melbourne's vegan restaurants.

\section{METHODOLOGY}

Using qualitative content analysis as the main research method, this research analysed text data, focusing on the language used by user-generated data in accordance with the contextual meaning of the content (Budd, Thorp \& Donohew, 1967; Lindkvist, 1981; McTavish \& Pirro, 1990; Tesch, 1990, cited in Hsieh \& Shannon, 2005). This research collected data from existing user-generated online reviews of Melbourne vegan restaurants with reviews on websites such as TripAdvisor and HappyCow. 


\section{FINDINGS}

This study has found with the aid of 50 reviews that food quality and service quality are invaluable factors that influence decision making. While there are more factors that could be considered like price and value, ambiance, and convenience, more studies need to be done create a more accurate picture of restaurant selection in vegan restaurants.

\section{CONCLUSION}

Today's modern customers are heavily influenced by the online reviews they find on the internet. Reviews on websites like TripAdvisor display the highly influential recommendations that either make or break the restaurant experience. As vegan restaurants are becoming a staple restaurant trend, more literature and studies are finding what influences customers to select a vegan restaurant.

\section{CONTRIBUTION/PRACTICAL IMPLICATIONS}

In terms of food quality, vegan restaurants should continue to focus on sub-factors of taste, menu variety, and presentation, which help ensure customer satisfaction. More often than not, restaurants only have one chance to make a good impression on guests.

One mistake on any of the aforementioned sub-factors could lead to a decline in customer revisits and the reputation of the restaurant. In terms of service quality, vegan restaurants should put as much focus on the service quality as they do with the food quality.

Customers are extremely receptive to the service of a restaurant which heavily influences the dining experience. Despite having good food quality, a restaurant that exhibits poor customer service will tarnish the entire experience.

\section{REFERENCES}

Chua, B. L., Karim, S., Lee, S., \& Han, H. (2020). Customer restaurant choice: An empirical analysis of restaurant types and eating-out occasions. International Journal of Environmental Research and Public Health, 17(17), 6276.

Lee, L., Lee, M. J., \& Dewald, B. (2016). Measuring the customers' perception of tangible service quality in the restaurant industry: An emphasis on the upscale dining segment. Journal of Foodservice Business Research, 19(1), 21-38.

Liu, P., \& Tse, E. C. Y. (2018). Exploring factors on customers' restaurant choice: An analysis of restaurant attributes. British Food Journal. 